\title{
A DIMENSÃO LINGUÍSTICO-DISCURSIVA DA MEMÓRIA NOSTÁLGICA NO ÂMBITO DE ESTRUTURA COMPOSICIONAL ${ }^{1}$
}

\author{
THE LINGUISTIC-DISCURSIVE DIMENSION OF \\ NOSTALGIC MEMORY IN THE SCOPE OF COMPOSITIONAL \\ STRUCTURE
}

\author{
Alana Destri \\ Universidade Estadual Paulista, Araraquara, São Paulo, Brasil \\ alanadestri@outlook.com
}

Anselmo Lima

Universidade Tecnológica Federal do Paraná, Pato Branco, Paraná, Brasil selmolima@hotmail.com

Resumo: Nostalgia é rememoração com apego emocional, um sentimento complexo e universal. Por ser algo vivido e compartilhado signicamente nas mais diversas esferas de interação humana, pode ser compreendido como algo profundamente linguístico-discursivo. Tendo isso em vista, enunciados nostálgicos foram o objeto de estudo para o aprofundamento científico sobre a dimensão discursiva do sentimento. Este artigo, em especial, visou explorar o padrão de manifestação nostálgica em relação à estrutura composicional do gênero editorial. Para tanto, fez-se uso de um corpus notoriamente nostálgico que conta com 106 editoriais da Revista Ferrovia publicados entre 1935 e 2017. A partir disso, utilizou-se de forma conectada o arcabouço teórico de gêneros do discurso de Mikhail Bakhtin e o psicossocial de Constantine Sedikides. À luz da teoria, as análises foram feitas e possibilitaram que certo padrão de manifestação fosse identificado e descrito, ampliando, assim, a compreensão do fenômeno em seu âmbito linguístico-discursivo.

Palavras-chave: Nostalgia; Gênero Discursivo; Estrutura Composicional

Abstract: Nostalgia is remembrance with emotional attachment, a complex and universal feeling. Because it is lived and shared through signs in the most diverse spheres of human interaction, it can be understood as something deeply linguistic-discursive. Thus, nostalgic utterances were used as study objects for the scientific deepening on the discursive dimension of the feeling. This article, in particular, aimed to explore the pattern of nostalgic manifestation in relation to the compositional structure of the genre. Therefore, a notoriously nostalgic corpus was used which has 106 Revista Ferrovia editorials published between 1935 and 2017. From this, the theoretical framework of Mikhail Bakhtin's Genres of discourse and the psychosocial theory of Constantine Sedikides were used in a connected way. In the light of the theory, the analyzes were made and enabled the identification and description of certain pattern of manifestation, thus broadening the understanding of the phenomenon in its linguistic-discursive scope.

Keywords: Nostalgia; Discursive Genre; Compositional structure

\footnotetext{
${ }^{1}$ Uma versão preliminar deste artigo foi apresentada na IV Jornada Internacional de Estudos do Discurso (2018).
} 


\section{INTRODUÇÃO}

Nostalgia é "lembrança sentimental do passado" (SEDIKIDES; WILDSHUT; BADEN, 2004, p. 203), mas, além de lidar com o passado e contrastá-lo com o presente, a nostalgia influencia de forma particular o futuro. É função chave da nostalgia facilitar o uso de percepções positivas com relação ao passado para reforçar a compreensão da continuidade entre o eu do passado e o eu do presente. No entanto, essas memórias não podem ser compartilhadas, perpetuadas e vividas senão através da linguagem. Compreender este fenômeno e saber identificá-lo é uma importante ferramenta para entender quem se é, na esfera em que se vive.

Dada a importância desse tópico na manutenção dos grupos sociais humanos, a dimensão discursiva da memória nostálgica foi objeto de estudo da dissertação apresentada em 2018 ao Programa de Pós-Graduação em Letras da Universidade Tecnológica Federal do Paraná - UTFPR intitulada "Aspectos da dimensão linguístico-discursiva da memória nostálgica: uma análise de editoriais da Revista Ferrovia" (DESTRI, 2018). Tal abordagem discursiva e dialógica da manifestação nostálgica, aparentemente, nunca fora feita no Brasil ou no exterior. $\mathrm{O}$ artigo aqui apresentado é um recorte que tem como objetivo estabelecer o modo relativamente estável com o qual a memória nostálgica permeia a estrutura composicional do discurso argumentativo do gênero editorial.

Para tanto, utilizou-se como corpus 106 editoriais da Revista Ferrovia, publicados pelo Órgão Oficial da Associação de Engenheiros da EFSJ - Estrada de ferro Santos-Jundiaí. A classe ferroviária, coletivo responsável pela revista, admite-se nostálgica e permeia de nostalgia seus discursos, o que torna o material interessante para a investigação científica aqui proposta.

O segmento ferroviário tem uma notável história de ascensão e queda. No século XVIII, acompanhando o êxito da produção cafeeira, foi um importante agente da transformação paulistana. Foi possuidor de um papel importante na colonização, agricultura e indústria. Em consequência, foi operador da imagem do estado e chave para o desenvolvimento econômico de diversas cidades, além de responsável pela fundação de muitas outras (MATOS, 1990). No entanto, com a crise mundial de 1929, o comércio de café brasileiro sofreu duras perdas. Nascida no seio cafeeiro, a esfera ferroviária não pôde deixar de sentir o impacto da crise. $\mathrm{O}$ ferroviário maltratado em uma organização doente passou a se sentir cada vez mais "frustrado, desiludido, egoísta, apático, sem ânimo, sem vida" (SOUZA, 1983, p. 187). A Revista Ferrovia surge nesse meio, buscando um melhor futuro para ferrovia sem deixar de relembrar nostalgicamente os tempos dourados.

Apresentado o contexto da ferrovia e da pesquisa que a circunda, tem-se a seguir o registro dos principais conceitos que regem a pesquisa. Em seguida, desenvolve-se o item sobre a aplicação da metodologia sobre o corpus, as análises e, por fim, as considerações finais. Neste item o resultado do processo foi exposto e as contribuições da pesquisa à esfera científica foram salientadas.

\section{GÊNERO DISCURSIVO E MEMÓRIA NOSTÁLGICA}

Segundo Bakhtin, "todos os diversos campos da atividade humana estão ligados ao uso da linguagem" (2016, p. 11). A unidade real da comunicação linguística são os enunciados, e às formas relativamente estáveis de enunciado dá-se o nome gêneros do discurso. Os gêneros discursivos são constituídos de quatro elementos coesos e inseparáveis. São eles 1) conteúdo temático, 2) estilo, 3) estrutura composicional e 4) relação interlocutiva (BAKHTIN, 2016, p. 11-12,39). A estrutura composicional, foco deste trabalho, refere-se aos materiais verbais e demais elementos convencionados à estrutura do gênero discursivo (SOBRAL, 2009, p. 97). 
O enunciado também tem a importante qualidade de ser "elo", ou "correia": "[o]s enunciados e seus tipos [...] são correias na transmissão entre história da sociedade e a história da linguagem" (BAKHTIN, 2016, p. 20). Ou seja, eles refletem em si as mudanças da sociedade e, em situação real de comunicação, repetem-se e recriam-se em uma correia ininterrupta, considerando os enunciados anteriores e prevendo os posteriores (BAKHTIN, 2016, p. 34-35).

Nessas trocas dialógicas, tratando-se agora das nostálgicas especificamente, há solidificação da identidade pessoal. Dela pode-se derivar um senso fortificado de individualidade, isto é, uma consciência individual gradualmente mais unificada através da reunião de peças mnemônicas da vida através da nostalgia. Além de solidificar a identidade, serve para protegê-la. Permite-se que o indivíduo 'escape' por alguns momentos de um presente medíocre ao restaurar mnemonicamente um passado altamente positivo. Através da glória refletida e de uma realização reexperimentada, a presente identidade adquire valor e uma nova aparência, tornando-se mais tolerável (SEDIKIDES; WILDSHUT; BADEN, 2004, p. 206).

Além de uma solidificação da identidade individual há também a da social. Ela sustenta e regenera o senso de significação também através de identificação cultural. Ou seja, a nostalgia alivia medos existenciais ao reforçar valores de tradição cultural e rituais nos quais o indivíduo já fez parte um dia. Logo, em vez de sentir solidão ou alienação, o processo nostálgico pode ser terapêutico - ele tem potencial de reforçar e revigorar traços de relacionamento interpessoais.

Após discorrer sobre teoria e contexto, versa-se, a seguir, sobre metodologia da pesquisa. Trata-se, portanto, dos procedimentos tomados sobre o corpus a fim de que, com a mobilização conjunta dos arcabouços teóricos, se construísse um todo significativo.

\section{DECISÕES METODOLÓGICOS}

Após a pesquisa bibliográfica com o fim de fundamentação teórica e do contato com o corpus, este foi ordenado cronologicamente. Após, os 106 editoriais foram expostos em um quadro de acordo com suas respectivas épocas de publicação, títulos e autores. Com isso, uma leitura minuciosa dos editoriais foi feita e os nostálgicos destacados. Para mapeá-los, foi necessária a produção de outros seis quadros. Os quadros desenvolvidos foram feitos baseandose nos elementos dos gêneros do discurso (BAKHTIN, 2016). O esquema de quadros, apêndices elaborados para a pesquisa integral, é o seguinte:

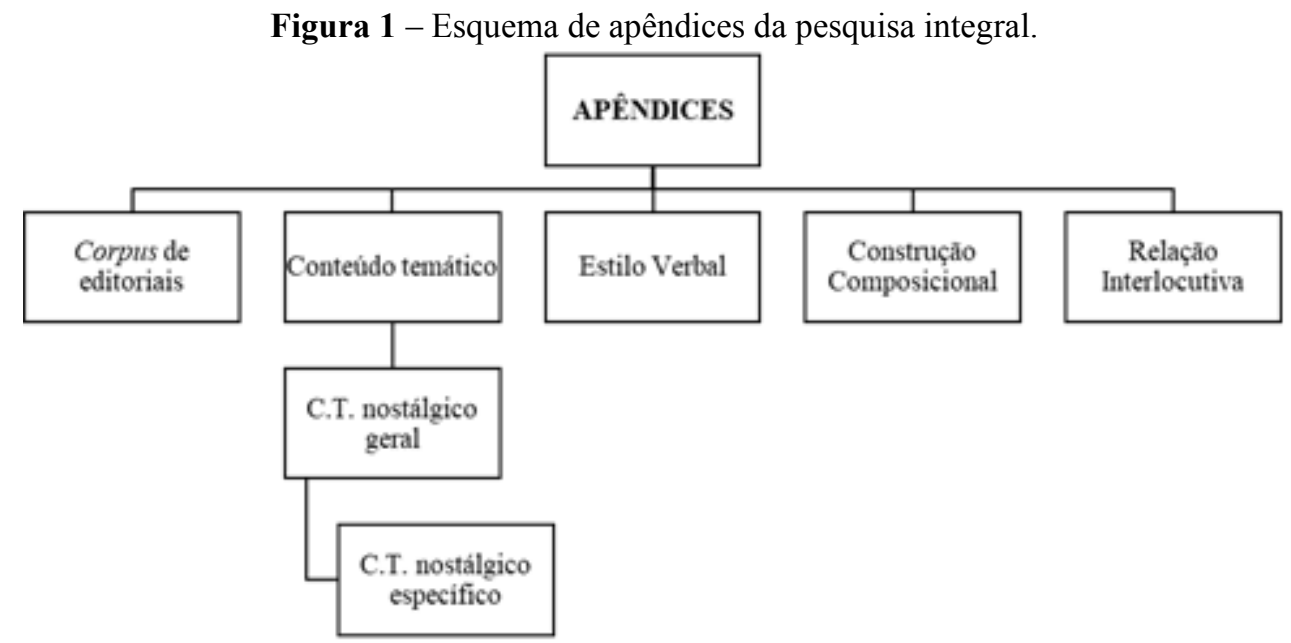

Fonte: elaborado pelos autores. 
Aqui são discutidos apenas os quadros que foram importantes para o objeto deste recorte. $\mathrm{O}$ terceiro quadro (Apêndice $\mathrm{A}$, neste artigo) visou à obtenção de informações sobre o conteúdo temático geral dos editoriais nostálgicos. Este foi dividido em colunas intituladas "Número", "Temática", "Passado", "Presente", "Futuro", "Nostalgia" e "Tendência".

"Número" refere-se ao das edições da Revista Ferrovia, postas em ordem cronológica da mais antiga para a mais recente. Em "Temática", observou-se um padrão de repetição de temas gerais. Os temas surgidos foram descritos como "Aconselhamento", "Adversidade", "Êxito", "Informação", "Mudança estrutural", "Perspectiva de êxito", "Prescrição", "Retrospectiva". Classificou-se como "Aconselhamento" a temática que conta com sugestões de comportamento, investimento ou planejamento empresarial. Em "Adversidade" a discussão gira em torno de empecilhos externos ou internos que inviabilizam um futuro próspero para a ferrovia. Os classificados assim geralmente trazem algum direcionamento que poderia auxiliar no sobrepujar do problema mencionado. O conteúdo de "Êxito" apresenta anúncio de vitórias concretas no ramo. O "Informação" traz um relatório de coisas importantes que aconteceram em determinados eventos. "Mudança estrutural" informa sobre mudanças que ocorreram ou ocorrerão na empresa. "Perspectiva de êxito" prevê melhorias significativas na esfera ferroviária. Em "Prescrição" há direcionamentos sobre como deve ser o trabalho do engenheiro ou ferroviário em geral. E, por fim, "Retrospectiva" é em relação aos editoriais de final de ano que contêm o conteúdo de relembrar o que houve na Rede. É válido lembrar que os editoriais comumente têm mais de um conteúdo temático e duas ou mais temáticas podem estar mescladas em um mesmo discurso. No entanto, consta aqui apenas a temática predominante.

Com relação às colunas "Passado", "Presente" e "Futuro", o "Passado" foi identificado como menção a um fato ocorrido em um passado longínquo. O "Presente" abrange desde o passado recente - que pouco se modifica do presente em questão situacional da ferrovia - até o momento em que se escreve o editorial. O "Futuro" está representado em predições e objetivos para o devir. E, finalizando, a coluna "Nostalgia" identifica os editoriais que possuem o citado sentimento de forma explícita. Tal identificação foi feita fazendo uso do conceito de "nostalgia" desenvolvido por Sedikides et al. (2008). Junto disso a tendência do editorialista a se referir sobre o futuro foi identificada como otimista (+), pessimista (-) ou indefinida (0).

Além deste quadro, outro foi desenvolvido para tornar possível uma análise satisfatória do conteúdo. Para o segundo, também usaram-se apenas os editoriais classificados como de manifestação explícita de nostalgia e o foco esteve no conteúdo temático específico (Apêndice B). Ou seja, foram elencados todos os editoriais nostálgicos na primeira coluna, na coluna a seguir seus parágrafos foram numerados e, para cada parágrafo, detalhou-se seu conteúdo temático específico. Para a descrição desta última coluna, priorizou-se a tendência temporal de discurso, visto que é algo que se liga diretamente ao cerne da nostalgia. O que não foi possível classificar como discurso sobre "presente", "passado" e "futuro" recebeu nomenclatura sobre sua função - proposta, hipótese ou pergunta retórica - o que, de certa forma, liga-se à noção de futuro.

Sobre construção composicional dos editoriais nostálgicos foi feito o sexto quadro (Apêndice C). Nele foram descritos os elementos "Número", "Ano", "Nome da sessão", "Diagramação", "Assinatura" e "Elementos periféricos". Ou seja, apresentam os dados do número de publicação em ordem cronológica, seu respectivo ano de publicação, o nome da sessão dada para o editorial, a forma de diagramação do texto, a configuração da assinatura e a lista dos elementos periféricos ao texto contidos em cada um dos editoriais.

Com os quadros feitos, buscou-se fazer aproximações dos dados com o intuito de delinear padrões. Para cada um dos quadros calcularam-se porcentagens de incidência além de ter seus dados cruzados com outros quadros. Com os resultados numéricos em mãos, as análises 
foram descritas intercaladas às tabelas de resultados, sempre levando em consideração os arcabouços teóricos regentes.

\section{ANÁLISE E RESULTADOS}

A estrutura composicional refere-se aos materiais verbais e demais elementos convencionados à estrutura do gênero discursivo (SOBRAL, 2009, p. 97). O gênero editorial de revista segue, portanto, uma estrutura definida e, no caso da Revista Ferrovia, altera-se com o tempo. As alterações são esperadas, pois os tipos relativamente estáveis de um gênero se modificam à medida que a esfera social da qual ele faz parte se modifica (BAKHTIN, 2016, p. 41). O período que compreende as revistas é de 1935 a 2017, o que resulta em 82 anos de existência e modificações na revista. Esta passou por transformações de material de impressão, de tiragem e política de assinatura. No entanto, a seção referente ao editorial se manteve intacta em todos as edições conseguidas, demonstrando assim fixidez no quadro de conteúdo. Com relação à estrutura observaram-se os componentes "nome da seção", "diagramação", "assinatura" e "elementos periféricos". Tudo isso atrelado ao ano de publicação dos editoriais nostálgicos e seu número respectivo de edição.

Nota-se que a estrutura do editorial da Revista Ferrovia se assemelha mais ao que se espera ver em um editorial de jornal do que em um de revista. O conteúdo sobre o interior da revista não é presente e a ênfase dada para problemas ligados diretamente ao momento de produção do texto deixa o texto com ares de editorial jornalístico - essencialmente argumentativo. Apenas no século XXI que os editoriais adquiriram traços de editorial de revista, visto que o texto passou a ser menos argumentativo, ter mais elementos periféricos e mais informações sobre o conteúdo da edição. Junto disso, ocorreu uma importante mudança na distribuição da revista: ela passou a ser principalmente disponibilizada via Internet.

Entre os nostálgicos, o nome da seção mudou de "Comentário" em 1967 para "Editorial" em 1971. Assim permaneceu até 1978 e, no final da década, o nome da seção foi suprimido e só voltou no novo milênio intitulando-se "Palavra da presidente". A diagramação oscilou entre o retangular tradicional e o triangular, como pode ser visto nas imagens a seguir.

Figura 4, 5 e 6 - Disposição do texto nos editoriais números 27, 73 e 171.

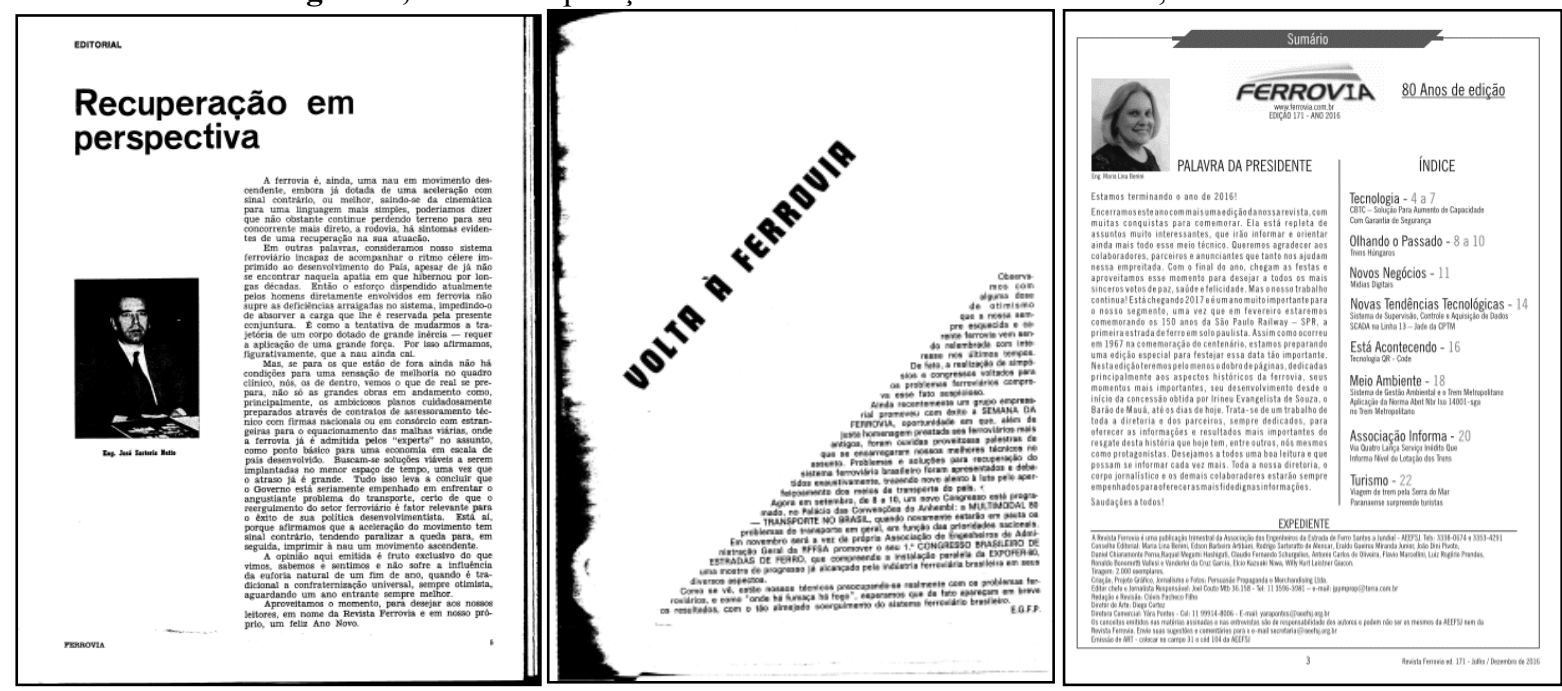

Fonte: acervo pessoal.

A mudança triangular vem, muito provavelmente, devido à situação da ferrovia, no qual o visual moderno da revista refletiria um momento de início de modernização ferroviária. 
A mudança nos editoriais nostálgicos se dá do retangular para o triangular no início de 1979 e volta a ser retangular em 2016. A assinatura era posta de forma completa até 78 . Desapareceu em 79 e voltou a aparecer como as iniciais no final de 79. A assinatura voltou a ser completa em editoriais nostálgicos apenas em 2016, com a editorialista Maria Lina Benini. Por fim, os elementos periféricos sempre foram poucos, mantendo em quase todas edições o rodapé com nome da revista e número da página. Houve durante um curto período (71-72) a foto do editorialista, algo que voltou na reformulação de 2016 que trouxe modificações também no que se trata de inclusão do índice, do expediente e do logo da revista.

Vale lembrar que as informações acima não são exclusivas dos editoriais nostálgicos. A mudança na estrutura e disposição dos elementos da publicação é independente de haver nostalgia nela ou não. Isto é, embora a nostalgia não influencie diretamente a mudança da estrutura composicional dos elementos textuais e paratextuais que caracterizam o gênero editorial, ela tem profunda significância na estruturação do discurso argumentativo do editorial da Revista. No texto argumentativo, há uma estrutura relativamente definida de utilização de nostalgia. Esse padrão de utilização altera-se dependendo do contexto em que o texto foi produzido. A fim chegar a essa análise, localizou-se os enunciados nostálgicos dentro do texto argumentativo para, após, buscar compreender as implicações da situação. Uma tabela foi feita para contabilizar as aparições de início, meio e/ou fim baseando-se no quadro de conteúdo temático específico de editoriais nostálgicos. Observe-se a primeira tabela.

Tabela 1: Localização de expressão de nostalgia explícita nos editoriais

\begin{tabular}{lll}
\hline Localização & $\begin{array}{l}\text { Número de } \\
\text { ocorrências }\end{array}$ & Porcentagem \\
\hline Início & 7 & $\mathbf{2 5 , 0 0 \%}$ \\
Meio & 5 & $\mathbf{1 7 , 8 6 \%}$ \\
Fim & 11 & $\mathbf{3 9 , 2 9 \%}$ \\
Início e fim & 2 & $\mathbf{7 , 1 4 \%}$ \\
Meio e fim & 1 & $\mathbf{3 , 5 7 \%}$ \\
Início, meio e fim & 2 & $\mathbf{7 , 1 4 \%}$ \\
\hline Total & 28 & $\mathbf{1 0 0 , 0 0 \%}$ \\
\hline
\end{tabular}

Fonte: elaborado pelos autores.

O número de editoriais que finalizam com manifestação da nostalgia lidera a contagem, tendo 11. Se contabilizada a classificação "Início e fim" juntamente com a "Meio e fim" e "Início, meio e fim", computam-se 16 editoriais que possuem encerramento nostálgico. 16 em um total de 28 é 57,14\%, porcentagem que se mostra significativa por abarcar mais da metade dos editoriais nostálgicos. A segunda localização mais comum é a do início, com 7 editoriais. Fazendo a contabilização total, os 11 editoriais têm a porcentagem de incidência em $39,29 \%$.

A partir disso, buscou-se compreender o que no contexto histórico, no processo de produção, influenciou nesses números. Esses dados obtidos foram cruzados com os dados sobre temática e tendência dos editoriais. A tabela a seguir mostra os resultados obtidos no cruzamento de informações entre localização (I, início; M, meio; F, fim; IF, início e fim; MF, meio e fim e IMF, início meio e fim) e temática principal do editorial. 
Tabela 2: Localização de expressão de nostalgia explícita nos editoriais por temática

\begin{tabular}{lllllll}
\hline Temática & I & M & F & IF & MF & IMF \\
\hline Aconselhamento & 0 & 1 & 0 & 0 & 0 & 1 \\
Adversidade & 3 & 1 & 2 & 2 & 1 & 0 \\
Êxito & 0 & 0 & 0 & 0 & 0 & 1 \\
Informativo & 0 & 0 & 0 & 1 & 0 & 0 \\
Mudança estrutural & 1 & 0 & 1 & 0 & 0 & 0 \\
Perspectiva de êxito & 0 & 2 & 5 & 1 & 0 & 0 \\
Prescrição & 0 & 0 & 3 & 0 & 0 & 1 \\
Retrospectiva & 0 & 1 & 0 & 0 & 0 & 0 \\
\hline
\end{tabular}

Fonte: elaborado pelos autores.

Na tabela se pode observar que há um destaque para traços nostálgicos no início do discurso quando este vem a ser sobre adversidade - um exemplo pode ser visto adiante. Computando o IF e o IMF em conjunto, nota-se que a predileção por iniciar o texto nostalgicamente se encontra em editoriais sobre adversidade, computando cinco ocorrências. Isso seguido por aconselhamento, informativo, mudança estrutural, perspectiva de êxito e prescrição - todos com uma ocorrência cada. Com relação aos editoriais que possuem nostalgia no meio de seu corpo linguístico, há uma sensível vantagem para editoriais com temática "perspectiva de êxito", "adversidade" e "aconselhamento" com a ocorrência de dois editoriais cada. Há também uma ocorrência em "êxito", "prescrição" e "retrospectiva". Quanto aos editoriais com manifestação nostálgica no fim, no meio e fim e no início meio e fim, aparece claramente uma predileção desta localização quando se trata de editoriais com perspectiva de êxito: seis no total. É seguido por "adversidade" com cinco, "prescrição" com quatro e, com uma ocorrência cada, encontram-se "aconselhamento", "êxito", "informativo" e "mudança estrutural”.

Além desta, há a tabela com o cruzamento de informações entre localização e tendência do editorialista sobre o futuro.

Tabela 3: Localização de expressão de nostalgia explícita nos editoriais por tendência.

\begin{tabular}{lllllll}
\hline Tendência & I & M & F & IF & IM & IMF \\
\hline Otimista & 0 & 1 & 8 & 3 & 0 & 1 \\
Pessimista & 1 & 1 & 1 & 0 & 0 & 0 \\
Indeterminado & 3 & 3 & 2 & 1 & 1 & 2 \\
\hline
\end{tabular}

Fonte: elaborado pelos autores.

Quando o editorialista estava em um contexto positivo para a ferrovia, o editorial era escrito com otimismo. Nesse aspecto, há uma clara vantagem de predileção pela conclusão nostálgica do discurso. Conta com oito ocorrências na classificação "fimm". Se contabilizado com IF e IMF, o número aumenta para doze editoriais com o final nostálgico, quatro com o início e dois com o meio. Os editoriais pessimistas, por sua vez, se distribuem, com uma ocorrência cada, entre início, meio e fim. Enfim, com a tendência indeterminada se contabilizam sete ocorrências no início, seis ocorrências no meio e cinco no final.

Em suma, o discurso inicia-se com nostalgia, principalmente em editoriais sobre adversidades, e encerra-se nostálgico principalmente em editoriais sobre perspectiva de êxito. Quando o editorial é otimista, geralmente encontra-se nostalgia no final do discurso, quando é aparentemente neutro (indeterminado), encontra-se no início. Tal resultado dá a entender que 
quando a situação da ferrovia está delicada, a nostalgia é evocada logo no início para sensibilizar o leitor para o problema apresentado a seguir. Quando é posta no fim, em conjunto com o otimismo de perspectiva de êxito, a nostalgia vem como horizonte a ser alcançado, motivando os ferroviários e patrocinadores na luta contínua de recuperação da ferrovia.

Um bom exemplo de editorial sobre adversidade que se inicia com sensibilização nostálgica é o "Publicidade negativa", escrito pelo engenheiro José Sartoris Netto (1971). Este editorial da edição 16 trata do problema da visão popular negativa que se avolumou sobre a estrada de ferro. O discurso inicia-se com "[n]ada mais bonito e decorativo do que uma pintura artisticamente colorida de uma velha locomotiva a vapor". Em seguida, o editorialista reconhece essa tendência geral como traço nostálgico do coletivo: "Procurando outra razão dessa preferência para o antigo, apontamos o fator saudosismo, ou melhor, o reconhecimento por "serviços prestados"".

Outro traço marcante da construção composicionais dos editoriais nostálgicos, a perspectiva de êxito com final nostálgico e inspirador, pode ser visto na edição número 57 . Nele, José Ferreira faz uma breve retrospectiva do ano de 1977 e prevê com otimismo o ano de 1978. Encerra o editorial da seguinte maneira:

[e]sses são nossos votos que, 77 seja o marco no destino das Ferrovias e graças ao espírito imbatível dos ferroviários, ela parta novamente para uma era de progresso e bom atendimento aos seus usuários e que 78 seja conhecido como o ano do novo crescimento da ferrovia no Brasil (FERREIRA, 1977).

O editorialista enaltece a classe de ferroviários adjetivando-os como de "espírito imbatível" na luta por melhorias na ferrovia e faz uso das expressões "parta novamente" e "novo" para falar de um futuro de sucesso. Logo, remete-se a antiga ferrovia, a do tempo de indubitável êxito, projetando-a animadoramente no devir.

\section{CONSIDERAÇÕES FINAIS}

O objetivo desta pesquisa foi estabelecer o modo com que a memória nostálgica, no âmbito de estrutura composicional, pode ser compreendida através do ponto de vista linguístico-discursivo. Para alcançá-lo, utilizou-se um corpus de editoriais nostálgicos da Revista Ferrovia, elencaram-se os conceitos necessários para o embasamento teórico bem como investigou-se o contexto histórico e de produção dos editoriais. Juntamente a essas etapas da pesquisa, um conjunto de outros procedimentos para a análise foram descritos no item sobre metodologia.

No segmento de análises pôde-se aprofundar o conhecimento dos padrões de manifestação da nostalgia no discurso com vista na estrutura composicional. Tais análises revelaram mudanças de construção de apresentação dos editoriais nas revistas. Voltando-se para o discurso, foi trazido à tona que há uma estrutura relativamente definida de utilização de nostalgia dependendo do contexto em que se encontra a ferrovia. Quando o editorial trata de forma neutra sobre adversidade, geralmente a nostalgia é colocada de forma introdutória, reativando a memória e sensibilizando o leitor. Em contrapartida, quando se trata com otimismo da perspectiva de êxito da ferrovia, a nostalgia é encaixada ao final do texto, motivando os ferroviários na luta por melhores condições da esfera.

A nostalgia em sua manifestação, portanto, é profundamente linguística e, em mesma proporção, social. A nostalgia é evocada em resposta a um afeto na existência do indivíduo. Em sua grande maioria das vezes, responde a um presente aflitivo e, segundo Sedikides et al., é 
uma força humana fundamental, parte importante da vida cotidiana, que serve como promotor de positividade, autoestima, ligações sociais e alívio das agruras do existir (2008, p. 307).

\section{REFERÊNCIAS}

BAKHTIN, Mikhail. Os gêneros do discurso. In: BAKHTN, Mikhail. Os gêneros do discurso. 1. ed. Trad. Paulo Bezerra. São Paulo: Editora 34, 2016. p. 09-70.

DESTRI, Alana. Aspectos da dimensão linguístico-discursiva da memória nostálgica: uma análise de editoriais da Revista Ferrovia. 2018. Dissertação - Programa de Pós-graduação em Letras, Universidade Tecnológica Federal do Paraná, Pato Branco, Paraná, 2018.

FERREIRA, José. Fim de ano. [Editorial]. Revista Ferrovia, n. 57, p. 5, nov./dez. 1977.

MATOS, Odilon Nogueira de. Café e ferrovias: a evolução ferroviária de São Paulo e o desenvolvimento da cultura cafeeira. Campinas, São Paulo: Pontes, 1990.

NETTO, José Sartoris. Publicidade negativa. [Editorial]. Revista Ferrovia, n. 16, p. 5, jan./fev. 1971.

SEDIKIDES, Constantine; WILDSCHUT, Tim; BADEN, Denise. Nostalgia: Conceptual Issues and Existential Functions. In: GREENBERG, Jeff; KOOLE, Sander Leon; PYSZCZYNSKI, Thomas A. (Orgs.). Handbook of Experimental Existential Psychology. Nova York: Guilford Publications, 2004, p. 200-215. Disponível em: http://studylib.net/doc/8267824/nostalgia---university-of-southampton. Acesso em: 13 ago. 2018.

SEDIKIDES, Constantine; WILDSCHUT, Tim; ARNDT, Jamie; ROUTLEDGE, Clay. Nostalgia: Past, Present, and Future. Current Directions in Psychological Science, n. 5. vol. 7. Washington D.C.: Association for Psychological Science, 2008. p. 304-307. Disponível em: http://www.wildschut.me/TimWildschut/home_files/Sedikides, $\% 20$ Wildschut, $\% 20$ Arndt, $\% 2$ 0\%26\%20Routledge,\%202008,\%20CDir.pdf. Acesso em: 13 ago. 2018.

SOBRAL, Adail. Do dialogismo ao gênero: as bases do pensamento do círculo de Bakhtin. Campinas, SP: Mercado de Letras, 2009.

SOUZA, Roberto de Mello E. Administração Integrada. São Paulo: Duas Cidades, 1983.

\section{APÊNDICE A - Quadro do conteúdo temático geral do corpus de editoriais que possuem manifestação de nostalgia}

\begin{tabular}{ccccccc}
\hline Número & Temática & Passado & Presente & Futuro & Nostalgia & Tendência \\
\hline $\mathbf{2}$ & Adversidade & $\mathrm{x}$ & $\mathrm{x}$ & $\mathrm{x}$ & $\mathrm{x}$ & 0 \\
\hline $\mathbf{1 6}$ & Adversidade & $\mathrm{x}$ & $\mathrm{x}$ & $\mathrm{x}$ & $\mathrm{x}$ & 0 \\
\hline $\mathbf{2 2}$ & Perspectiva de êxito & $\mathrm{x}$ & $\mathrm{x}$ & $\mathrm{x}$ & $\mathrm{x}$ & + \\
\hline
\end{tabular}




\begin{tabular}{|c|c|c|c|c|c|c|}
\hline 24 & Adversidade & $\mathrm{x}$ & $\mathrm{x}$ & $\mathrm{x}$ & $\mathrm{x}$ & - \\
\hline 34 & Perspectiva de êxito & $\mathrm{x}$ & $\mathrm{x}$ & $\mathrm{x}$ & $\mathrm{x}$ & + \\
\hline 35 & Adversidade & $\mathrm{x}$ & $\mathrm{x}$ & $\mathrm{x}$ & $\mathrm{x}$ & - \\
\hline 36 & Adversidade & $\mathrm{x}$ & $\mathrm{x}$ & $\mathrm{x}$ & $\mathrm{x}$ & 0 \\
\hline 41 & Adversidade & $\mathrm{x}$ & $\mathrm{x}$ & $\mathrm{x}$ & $\mathrm{x}$ & 0 \\
\hline 47 & Perspectiva de êxito & $\mathrm{x}$ & $\mathrm{x}$ & $\mathrm{x}$ & $\mathrm{x}$ & + \\
\hline 52 & Aconselhamento & $\mathrm{x}$ & $\mathrm{x}$ & $\mathrm{x}$ & $\mathrm{x}$ & 0 \\
\hline 56 & Prescrição & $\mathrm{x}$ & $\mathrm{x}$ & $\mathrm{x}$ & $\mathrm{x}$ & + \\
\hline 57 & Perspectiva de êxito & $\mathrm{x}$ & $\mathrm{x}$ & $\mathrm{x}$ & $\mathrm{x}$ & + \\
\hline 58 & Prescrição & $\mathrm{x}$ & $\mathrm{x}$ & $\mathrm{x}$ & $\mathrm{x}$ & 0 \\
\hline 62 & Mudança estrutural & $\mathrm{x}$ & $\mathrm{x}$ & $\mathrm{x}$ & $\mathrm{x}$ & 0 \\
\hline 67 & Adversidade & $\mathrm{x}$ & $\mathrm{x}$ & $\mathrm{x}$ & $\mathrm{x}$ & 0 \\
\hline 68 & Adversidade & $\mathrm{x}$ & $\mathrm{x}$ & $\mathrm{x}$ & $\mathrm{x}$ & - \\
\hline 69 & Prescrição & $\mathrm{x}$ & $\mathrm{x}$ & $\mathrm{x}$ & $\mathrm{x}$ & + \\
\hline 70 & Perspectiva de êxito & $\mathrm{x}$ & $\mathrm{x}$ & $\mathrm{x}$ & $\mathrm{x}$ & + \\
\hline 71 & Informação - evento & $\mathrm{x}$ & $\mathrm{x}$ & $\mathrm{x}$ & $\mathrm{x}$ & + \\
\hline 73 & Perspectiva de êxito & $\mathrm{x}$ & $\mathrm{x}$ & $\mathrm{x}$ & $\mathrm{x}$ & + \\
\hline 75 & Perspectiva de êxito & $\mathrm{x}$ & $\mathrm{x}$ & $\mathrm{x}$ & $\mathrm{x}$ & 0 \\
\hline 76 & Prescrição & $\mathrm{x}$ & $\mathrm{x}$ & $\mathrm{x}$ & $\mathrm{x}$ & + \\
\hline 77 & Perspectiva de êxito & $\mathrm{x}$ & $\mathrm{x}$ & $\mathrm{x}$ & $\mathrm{x}$ & + \\
\hline 78 & Perspectiva de êxito & $\mathrm{x}$ & $\mathrm{x}$ & $\mathrm{x}$ & $\mathrm{x}$ & + \\
\hline 82 & Mudança estrutural & $\mathrm{x}$ & $\mathrm{x}$ & $\mathrm{x}$ & $\mathrm{x}$ & + \\
\hline 170 & Aconselhamento & $\mathrm{x}$ & $\mathrm{x}$ & $\mathrm{x}$ & $\mathrm{x}$ & 0 \\
\hline 171 & Retrospectiva & $\mathrm{x}$ & $\mathrm{x}$ & $\mathrm{x}$ & $\mathrm{x}$ & 0 \\
\hline 172 & Exxito & $\mathrm{x}$ & $\mathrm{x}$ & $x$ & $\mathrm{x}$ & + \\
\hline
\end{tabular}

\section{APÊNDICE B - Quadro do conteúdo temático específico do corpus de} editoriais que possuem manifestação de nostalgia

\begin{tabular}{|c|c|c|c|}
\hline Número & Temática & Parágrafos & Temática por parágrafo \\
\hline \multirow[t]{8}{*}{2} & Adversidade & 14 & 1 - Presente (nostalgia) \\
\hline & & & 2 - Passado (nostalgia) \\
\hline & & & 3 - Presente \\
\hline & & & 4 - Presente \\
\hline & & & 5 - Presente \\
\hline & & & 6 - Presente \\
\hline & & & 7 - Pergunta retórica \\
\hline & & & 8 - Passado \\
\hline
\end{tabular}




\begin{tabular}{|c|c|c|c|}
\hline & & & 9 - Passado \\
\hline & & & 10 - Passado \\
\hline & & & 11 - Pergunta retórica \\
\hline & & & 12 - Futuro \\
\hline & & & 13 - Presente \\
\hline & & & 14 - Proposta de solução \\
\hline \multirow[t]{13}{*}{16} & \multirow[t]{13}{*}{ Adversidade } & \multirow[t]{13}{*}{13} & 1 - Presente (nostalgia) \\
\hline & & & 2 - Presente \\
\hline & & & 3 - Presente (nostalgia) \\
\hline & & & 4 - Passado \\
\hline & & & 5 - Passado (nostalgia) \\
\hline & & & 6 - Presente \\
\hline & & & 7 - Presente (nostalgia) \\
\hline & & & 8 - Presente \\
\hline & & & 9 - Presente \\
\hline & & & 10 - Hipótese \\
\hline & & & 11 - Presente \\
\hline & & & 12 - Hipótese \\
\hline & & & 12 - Proposta de solução \\
\hline \multirow[t]{17}{*}{22} & \multirow[t]{17}{*}{ Perspectiva de êxito } & \multirow[t]{17}{*}{17} & $1-$ Futuro \\
\hline & & & 2 - Presente \\
\hline & & & 3 - Passado \\
\hline & & & 4 - Passado \\
\hline & & & 5 - Passado \\
\hline & & & 6 - Passado \\
\hline & & & 7 - Presente \\
\hline & & & 8 - Passado \\
\hline & & & 9 - Passado \\
\hline & & & 10 - Passado \\
\hline & & & 11 - Presente \\
\hline & & & 12 - Presente \\
\hline & & & 13 - Futuro \\
\hline & & & 14 - Presente \\
\hline & & & $15-$ Futuro \\
\hline & & & 16 - Presente \\
\hline & & & 17 - Futuro (nostalgia) \\
\hline \multirow[t]{4}{*}{24} & \multirow[t]{4}{*}{ Adversidade } & \multirow[t]{4}{*}{9} & 1 - Passado (nostalgia) \\
\hline & & & 2 - Passado \\
\hline & & & 3 - Passado \\
\hline & & & 4 - Passado \\
\hline
\end{tabular}




\begin{tabular}{|c|c|c|c|}
\hline & & & 5 - Presente \\
\hline & & & 6 - Presente \\
\hline & & & 10 - Presente \\
\hline & & & 11 - Presente \\
\hline & & & 12 - Proposta de solução \\
\hline \multirow[t]{10}{*}{34} & \multirow[t]{10}{*}{ Adversidade } & \multirow[t]{10}{*}{10} & 1 - Presente \\
\hline & & & 2 - Presente (nostalgia) \\
\hline & & & 3 - Presente \\
\hline & & & 4 - Presente \\
\hline & & & 5 - Presente \\
\hline & & & 6 - Presente \\
\hline & & & 7 - Presente \\
\hline & & & 8 - Presente \\
\hline & & & 9 - Proposta de solução \\
\hline & & & 10 - Proposta de solução (nostalgia) \\
\hline \multirow[t]{8}{*}{35} & \multirow[t]{8}{*}{ Adversidade } & \multirow[t]{8}{*}{8} & 1 - Presente \\
\hline & & & 2 - Pergunta retórica \\
\hline & & & 3 - Presente \\
\hline & & & 4 - Pergunta retórica \\
\hline & & & 5 - Passado (nostalgia) \\
\hline & & & 6 - Proposta de solução \\
\hline & & & 7 - Proposta de solução \\
\hline & & & 8 - Proposta de solução \\
\hline \multirow[t]{8}{*}{36} & \multirow[t]{8}{*}{ Adversidade } & \multirow[t]{8}{*}{8} & 1 - Presente (nostalgia) \\
\hline & & & 2 - Presente \\
\hline & & & 3 - Presente \\
\hline & & & 4 - Perguntas retóricas \\
\hline & & & 5 - Presente \\
\hline & & & 6 - Presente \\
\hline & & & 7 - Proposta de solução \\
\hline & & & $8-$ Futuro \\
\hline \multirow[t]{9}{*}{41} & \multirow[t]{9}{*}{ Adversidade } & \multirow[t]{9}{*}{13} & 1 - Pergunta retórica \\
\hline & & & 2 - Passado (nostalgia) \\
\hline & & & 3 - Presente \\
\hline & & & 4 - Presente \\
\hline & & & 5 - Presente \\
\hline & & & 6 - Presente \\
\hline & & & 7 - Presente \\
\hline & & & 8 - Presente \\
\hline & & & $9-$ Futuro \\
\hline
\end{tabular}




\begin{tabular}{|c|c|c|c|}
\hline & & & 10 - Presente \\
\hline & & & 11 - Presente \\
\hline & & & 12 - Presente \\
\hline & & & 13 - Futuro (nostalgia) \\
\hline \multirow[t]{9}{*}{47} & \multirow[t]{9}{*}{ Perspectiva de êxito } & \multirow[t]{9}{*}{9} & 1 - Presente \\
\hline & & & 2 - Presente \\
\hline & & & 3 - Presente \\
\hline & & & 4 - Passado (nostalgia) \\
\hline & & & 5 - Presente \\
\hline & & & 6 - Presente \\
\hline & & & 7 - Futuro \\
\hline & & & $8-$ Futuro \\
\hline & & & 9 - Agradecimento \\
\hline \multirow[t]{6}{*}{52} & \multirow[t]{6}{*}{ Aconselhamento } & \multirow[t]{6}{*}{6} & 1 - Presente \\
\hline & & & 2 - Aconselhamento \\
\hline & & & 3 - Aconselhamento \\
\hline & & & 4 - Aconselhamento \\
\hline & & & 5 - Aconselhamento (nostalgia) \\
\hline & & & $6-$ Futuro \\
\hline \multirow[t]{6}{*}{56} & \multirow[t]{6}{*}{ Prescrição } & \multirow[t]{6}{*}{6} & 1 - Presente \\
\hline & & & $2-$ Futuro \\
\hline & & & 3 - Prescrição \\
\hline & & & 4 - Presente \\
\hline & & & 5 - Presente \\
\hline & & & 6 - Prescrição (nostalgia) \\
\hline \multirow[t]{3}{*}{57} & \multirow[t]{3}{*}{ Perspectiva de êxito } & \multirow[t]{3}{*}{3} & 1 - Presente \\
\hline & & & 2 - Futuro \\
\hline & & & 3 - Futuro (nostalgia) \\
\hline \multirow[t]{5}{*}{58} & \multirow[t]{5}{*}{ Prescrição } & \multirow[t]{5}{*}{5} & 1 - Passado (nostalgia) \\
\hline & & & 2 - Presente \\
\hline & & & 3 - Presente (nostalgia) \\
\hline & & & 4 - Prescrição (nostalgia) \\
\hline & & & 5 - Prescrição (nostalgia) \\
\hline \multirow[t]{5}{*}{62} & \multirow[t]{5}{*}{ Mudança estrutural } & \multirow[t]{5}{*}{5} & 1 - Presente \\
\hline & & & 2 - Presente \\
\hline & & & 3 - Presente \\
\hline & & & 4 - Presente \\
\hline & & & 5 - Proposta de solução (nostalgia) \\
\hline \multirow[t]{3}{*}{67} & \multirow[t]{3}{*}{ Adversidade } & \multirow[t]{3}{*}{6} & $1-$ Passado \\
\hline & & & 2 - Presente \\
\hline & & & 3 - Pergunta retórica \\
\hline
\end{tabular}




\begin{tabular}{|c|c|c|c|}
\hline & & & 4 - Pergunta retórica \\
\hline & & & 5 - Pergunta retórica \\
\hline & & & 6 - Futuro (nostalgia) \\
\hline \multirow[t]{5}{*}{68} & \multirow[t]{5}{*}{ Adversidade } & \multirow[t]{5}{*}{5} & 1 - Presente \\
\hline & & & 2 - Presente \\
\hline & & & 3 - Presente \\
\hline & & & 4 - Presente \\
\hline & & & 5 - Futuro (nostalgia) \\
\hline \multirow[t]{6}{*}{69} & \multirow[t]{6}{*}{ Prescrição } & \multirow[t]{6}{*}{6} & $1-$ Futuro \\
\hline & & & $2-$ Futuro \\
\hline & & & $3-$ Futuro \\
\hline & & & $4-$ Futuro \\
\hline & & & $5-$ Futuro \\
\hline & & & 6 - Futuro (nostalgia) \\
\hline \multirow[t]{4}{*}{70} & \multirow[t]{4}{*}{ Perspectiva de êxito } & \multirow[t]{4}{*}{4} & 1 - Presente \\
\hline & & & $2-$ Futuro \\
\hline & & & 3 -Presente \\
\hline & & & 4 - Futuro (nostalgia) \\
\hline \multirow[t]{4}{*}{71} & \multirow[t]{4}{*}{ Informação - evento } & \multirow[t]{4}{*}{4} & 1 - Passado (nostalgia) \\
\hline & & & 2 - Presente \\
\hline & & & 3 - Presente \\
\hline & & & 4 - Futuro (nostalgia) \\
\hline \multirow[t]{4}{*}{73} & \multirow[t]{4}{*}{ Perspectiva de êxito } & \multirow[t]{4}{*}{4} & 1 - Presente \\
\hline & & & 2 - Presente \\
\hline & & & 3 - Presente \\
\hline & & & 4 - Futuro (nostalgia) \\
\hline \multirow[t]{3}{*}{75} & \multirow[t]{3}{*}{ Perspectiva de êxito } & \multirow[t]{3}{*}{3} & 1 - Presente \\
\hline & & & 2 - Presente (nostalgia) \\
\hline & & & 3 - Agradecimento \\
\hline \multirow[t]{5}{*}{76} & \multirow[t]{5}{*}{ Prescrição } & \multirow[t]{5}{*}{5} & 1 - Presente \\
\hline & & & 2 - Presente \\
\hline & & & 3 - Presente \\
\hline & & & 4 - Prescrição (nostalgia) \\
\hline & & & 5 - Prescrição (nostalgia) \\
\hline \multirow[t]{7}{*}{77} & \multirow[t]{7}{*}{ Perspectiva de êxito } & \multirow[t]{7}{*}{7} & 1 - Presente \\
\hline & & & $2-$ Futuro \\
\hline & & & 3 - Futuro \\
\hline & & & $4-$ Futuro \\
\hline & & & $5-$ Futuro \\
\hline & & & $6-$ Futuro \\
\hline & & & 7 - Futuro (nostalgia) \\
\hline
\end{tabular}




\begin{tabular}{|c|c|c|c|}
\hline \multirow[t]{2}{*}{78} & \multirow[t]{2}{*}{ Perspectiva de êxito } & \multirow[t]{2}{*}{2} & 1 - Presente (nostalgia) \\
\hline & & & 2 - Presente \\
\hline \multirow[t]{5}{*}{82} & \multirow[t]{5}{*}{ Mudança estrutural } & \multirow[t]{5}{*}{5} & 1 - Passado (nostalgia) \\
\hline & & & 2 - Presente \\
\hline & & & 3 -Presente \\
\hline & & & $4-$ Futuro \\
\hline & & & $5-$ Futuro \\
\hline 170 & Aconselhamento & 1 & 1 - Presente (nostalgia) \\
\hline \multirow[t]{3}{*}{171} & \multirow[t]{3}{*}{ Retrospectiva } & \multirow[t]{3}{*}{3} & 1 - Saudação \\
\hline & & & 2 - Futuro (nostalgia) \\
\hline & & & 3 - Saudação \\
\hline 172 & Exxito & 1 & 1 - Presente (nostalgia) \\
\hline
\end{tabular}

\section{APÊNDICE C - Quadro sobre construção composicional do corpus de editoriais que possuem manifestação de nostalgia}

\begin{tabular}{|c|c|c|c|c|c|c|}
\hline Número & Ano & $\begin{array}{l}\text { Pará- } \\
\text { grafos }\end{array}$ & $\begin{array}{l}\text { Nome da } \\
\text { sessão }\end{array}$ & Diagramação & Assinatura & $\begin{array}{l}\text { Elementos } \\
\text { periféricos }\end{array}$ \\
\hline 2 & 1967 & 14 & Comentário & 1 coluna retangular & Completa & Rodapé \\
\hline 16 & 1971 & 13 & Editorial & 1 coluna retangular & Completa & $\begin{array}{c}\text { Fotografia } \\
\text { do autor e } \\
\text { rodapé }\end{array}$ \\
\hline 22 & 1972 & 17 & Editorial & 1 coluna retangular & Completa & $\begin{array}{c}\text { Fotografia } \\
\text { do autor e } \\
\text { rodapé }\end{array}$ \\
\hline 24 & 1972 & 9 & Editorial & 1 coluna retangular & Completa & $\begin{array}{c}\text { Fotografia } \\
\text { do autor e } \\
\text { rodapé }\end{array}$ \\
\hline 34 & 1974 & 10 & Editorial & 1 coluna retangular & Completa & Rodapé \\
\hline 35 & 1974 & 8 & Editorial & 1 coluna retangular & Completa & Rodapé \\
\hline 36 & 1974 & 8 & Editorial & 1 coluna retangular & Completa & Rodapé \\
\hline 41 & 1975 & 13 & Editorial & 1 coluna retangular & Completa & Rodapé \\
\hline 47 & 1976 & 9 & Editorial & 1 coluna retangular & Completa & Rodapé \\
\hline 52 & 1977 & 6 & Editorial & 1 coluna retangular & Completa & Rodapé \\
\hline 56 & 1977 & 6 & Editorial & 1 coluna retangular & Completa & Rodapé \\
\hline 57 & 1977 & 3 & Editorial & 1 coluna retangular & Completa & Rodapé \\
\hline 58 & 1978 & 5 & Editorial & 1 coluna retangular & Completa & Rodapé \\
\hline 62 & 1978 & 5 & Editorial & 1 coluna retangular & Completa & Rodapé \\
\hline 67 & 1979 & 6 & - & Triangular & - & Rodapé \\
\hline 68 & 1979 & 5 & - & Triangular & - & Rodapé \\
\hline 69 & 1979 & 6 & - & Triangular & Iniciais & Rodapé \\
\hline 70 & 1980 & 4 & - & Triangular & Iniciais & Rodapé \\
\hline 71 & 1980 & 4 & - & Triangular & Iniciais & Rodapé \\
\hline 73 & 1980 & 4 & - & Triangular & Iniciais & Rodapé \\
\hline 75 & 1980 & 3 & - & Triangular & Iniciais & Rodapé \\
\hline
\end{tabular}




\begin{tabular}{|c|c|c|c|c|c|c|}
\hline 76 & 1981 & 5 & - & Triangular & Iniciais & Rodapé \\
\hline 77 & 1981 & 7 & - & Triangular & Iniciais & Rodapé \\
\hline 78 & 1981 & 2 & - & Triangular & Iniciais & Rodapé \\
\hline 82 & 1982 & 5 & - & Triangular & Iniciais & Rodapé \\
\hline 170 & 2016 & 1 & $\begin{array}{l}\text { Palavra da } \\
\text { Presidente }\end{array}$ & 1 coluna retangular & Completa & $\begin{array}{l}\text { Logo da } \\
\text { revista, } \\
\text { fotografia do } \\
\text { autor, índice, } \\
\text { expediente, } \\
\text { rodapé }\end{array}$ \\
\hline 171 & 2016 & 3 & $\begin{array}{l}\text { Palavra da } \\
\text { presidente }\end{array}$ & 1 coluna retangular & Completa & $\begin{array}{l}\text { Logo da } \\
\text { revista, } \\
\text { fotografia do } \\
\text { autor, índice, } \\
\text { expediente, } \\
\text { rodapé }\end{array}$ \\
\hline 172 & 2017 & 1 & $\begin{array}{l}\text { Palavra da } \\
\text { presidente }\end{array}$ & $\begin{array}{l}2 \text { colunas } \\
\text { retangulares }\end{array}$ & Completa & $\begin{array}{c}\text { Cabeçalho, } \\
\text { fotografia do } \\
\text { autor, } \\
\text { imagem } \\
\text { ilustrativa }\end{array}$ \\
\hline
\end{tabular}

Recebido em: 26 de janeiro de 2019

Aceito em: 05 de setembro de 2019

Publicado em Maio de 2020 